\title{
EXTENDING THE AERIAL
}

\section{UNCOVERING HISTORIES OF TELETEXTAND TELESOFTWARE IN BRITAIN}

\author{
Alison Gazzard \\ Lecturer in Media Arts \\ London Knowledge Lab \\ UCL Institute of Education \\ 23-29 Emerald Street \\ London, WC1N 3QS \\ alison.gazzard@ucl.ac.uk
}

\begin{abstract}
Beyond their roles of broadcasting programmed content into the homes of people around the country, Britain's British Broadcasting Corporation and Independent Television stations delivered additional content via home television sets. This article will explore the history of British teletext and telesoftware in the broader context of microprocessing developments during the late 1970s and early 1980s through a media archaeological framework of the terminology and traits. Situating these developments in the industrial and political climates of the 1970s, the article will outline an alternative history of networks through the aerial, as the 'hidden lines' of information become exposed once again.
\end{abstract}

Keywords: Britain, teletext, telesoftware, media archaeology, convergence

\section{Introduction}

Television should now be seen, not in isolation, but as one of a number of information and communication technologies occupying domestic time and space alongside the video-recorder, the computer and the telephone, as well as the Walkman, the answering-machine, the stereo and the radio. ${ }^{1}$

Although he was writing in the early 1990s, David Morley's observations of television's role in domestic space also apply to the present moment. Part of a suite of other technologies in the home, TV has become a facilitator of both media and technological 'convergence,' defined in part by Henry Jenkins as "the flow of content across multiple media platforms." 2 Television's ability to link DVD and VCR players and recorders, video game consoles and microcomputers shows how the role and use of television has shifted across time. As such, in 2015, the television is often labelled 'smart' by companies and marketers. The smart television allows users to access content via the Internet and to use on-demand 
programmes as well as software applications including games. This rise in so-called smart television sets in the last decade underscores that television, often thought of as 'old media,' remains 'new media.'

Television as new media is the subject of Sheila Murphy's book How Television Invented New Media, in which the author argues that TV today is "a deeply digital, interactive device mediated by the manipulation of both hardware (the remote) and software (the onscreen guide to the TV's settings and the program guide for navigating content)." ${ }^{3}$ For Murphy, television's newness is partly dependent on the recent integration of programs and applications into its infrastructure.

While it is broadly acknowledged that software is a central component of current television technologies, the role of software in TV before the current digital age is less recognized. As Manovich notes, "We live in a software culture - that is, a culture where the production, distribution, and reception of most content is mediated by software."4 However, software culture is not only a fact of the present day. Software cultures have a longer history linked to computer hardware, production, and use: television's convergence with software cultures dates back to the developments of microcomputing technologies in the 1970s and 1980s.

Whereas the Internet and connectivity are often discussed in terms of the 'network society' that supposedly emerged in the 1990s, scholars such as Jay McKinnon have noted earlier instances of convergent media. ${ }^{5}$ From a European perspective, it can be seen that traits of what is now described as the smart television set can be traced back to the late 1970 s and early 1980s and the development of interactive videotex and viewdata.

In Britain, interactive videotex services were introduced by the Post Office and, subsequently, British Telecom through their Prestel service. Prestel was a two-way interactive system that enabled people to connect to information databases via their telephone service and a dedicated terminal or adapter; it was also possible for users to make bookings through the system for theatre tickets, holidays, and other services.

The histories of these videotex and viewdata are discussed in the work of Susanne Schmidt and Raymund Werle, Jerome Aumente and Richard Veith, in which they are also studied in relation to the teletext services that are offered globally. ${ }^{6}$ In contrast to videotex, teletext services provided one way communication, available via the user's television aerial and a compatible TV set, or by connecting a teletext adapter to the TV set. As recognized by Schmidt and Werle, "the UK's lead was significant" in relation to both videotex and teletext services. ${ }^{7}$ However, what many of these histories miss is how these services were marketed and used by the public, as well as how they were placed alongside other, more localized developments in the history of technology.

This article examines the history of teletext and telesoftware in Britain and discusses in particular the terminology employed for marketing, producing and using teletext. It draws from advertisements for teletext adapters and a range of magazines that focused on the role of domestic computers in the 1980s. The sources reveal how these technologies and services were operated in relation to other media and uncover uses of teletext in the form of downloadable telesoftware programs. The use of telesoftware was enabled by Britain's increasing developments in microcomputing during the late 1970s and 1980s, which led to the production of machines such as the BBC Microcomputer and the ZX Spectrum (see Figure 1).

In their introductions to the field of media archaeology, Parikka and Huhtamo reference the need to highlight 'alternative' histories of media discourse by examining the 'suppressed' or 'neglected' histories of media's past in relation to their future constructs. ${ }^{8}$ By tracing developments in teletext, and subsequent telesoftware services, we can discuss these

3 Sheila C. Murphy, How Television Invented New Media, Rutgers University Press, 2011, p. 3.

4 Lev Manovich, Software Takes Command, Bloomsbury Academic, 2013, p. 39.

5 Jay Kelly McKinnon, Post-Modemism: The Role of User Adoption of Teletext, Videotex and Bulletin Board Systems in the History of the Internet, MA Thesis, Simon Fraser University, 2012.

6 Susanne K. Schmidt and Raymund Werle, Coordinating Technology: Studies in the International Standardization of Telecommunications, MIT Press, 1998; Jerome Aumente, New Electronic Pathways: Videotex, Teletext, and Online Databases, Sage Publications, 1987; Richard H. Veith, Television's Teletext, Elseview Science Publishing Co., 1983.

7 Schmidt and Werle, p. 166.

8 Jussi Parikka, What Is Media Archaeology?, Polity Press, 2012. 
often 'neglected' technologies that play a role in the histories of networked information. By situating some of these developments in the industrial and political climates of the 1970s, this article thus outlines an alternative history of networks through the aerial. The outcomes of these findings are situated in a wider academic discourse about new media technologies and convergence cultures to show the cycles of media distribution offered by a media archaeological approach.

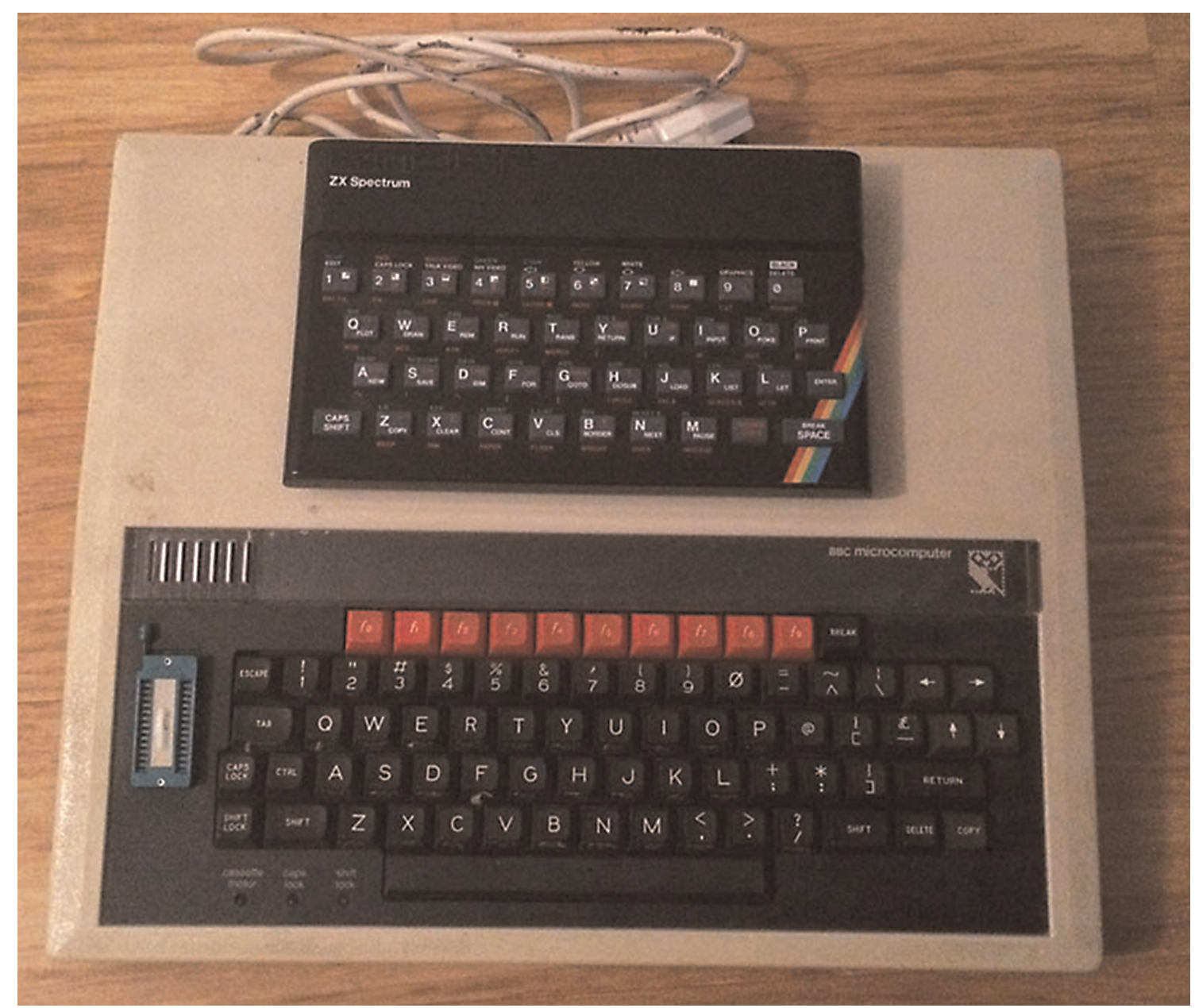

Fig. 1 ZX Spectrum (top), BBC Microcomputer (underneath).

\section{A British History of Teletext}

Until the early 1980s, three main terrestrial channels were available in Britain: BBC One, BBC Two and ITV (Independent Television). They were followed by Channel 4 in 1982, and Channel 5 in 1997. The British Broadcasting Corporation (BBC) and the Independent Television stations were at the heart of the initial developments in television communications. Interested in extending their services, the institutions investigated possibilities for offering access to the hard of hearing and deaf communities and sought to transform the TV set into an information console. The lowering cost of silicon chips allowed for developing extra television peripherals and services including teletext. ${ }^{9}$ 
Teletext was a one-way means of delivering information through cycled page numbers. Teletext pages were broadcast using the standard television signal, utilizing the unused scan lines to deliver extra data via the aerial. The pages displayed text as well as basic graphics. As an article in The Home Computer Course from 1983 notes:

the signals that define a teletext page are transmitted between frames of a normal television picture. A decoding device separates them out and creates the teletext image. The resulting text and graphics can displace the normal broadcast picture or be superimposed over it so that the two appear together, as when teletext is used to provide subtitles for the hard of hearing. ${ }^{10}$

The information offered on these pages included football scores, flight arrival details, stocks and shares, and television listings.

A winter edition of the Eng Inf quarterly publication for BBC Engineering Staff details how, "It was Peter Rainger who, as Head of Designs Department, first laid the framework of the Teletext system in 1970 and became one of its copatentees in 1972."11 This was later taken over by John Chambers, the Head of the Special Projects section, who was the author of the teletext technical specification published in 1976. Following the BBC's initial developments in prototyping the teletext system, it was decided in 1972 that further consultation with industry and support from ITV would insure the future success of the project. Richard Veith relates that "a committee comprised of representatives from the BBC, ITV, the semiconductor industry, and the television manufacturing industry was established to design a suitable system standard." ${ }^{12}$ These discussions resulted in the BBC developing a teletext system titled Ceefax ('see facts') and in ITV producing its own version titled ORACLE (Optional Reception of Announcements by Coded Line Electronics).

In his 1983 book titled Television's Teletext, Veith continues to outline why the need for two versions was important. ${ }^{13} \mathrm{He}$ comments upon how the success of the teletext project by the BBC was only really going to be possible with the support of television set manufacturers because they would provide the internal teletext decoders or external adapters. Creating a common standard for teletext systems was another central criterion for the success of any service even if it was being used by different organisations. As McKinnon notes, it was by "using a common data protocol [that] these systems established a protocol commonly referred to as 'British Context,' later extended to 'World System Teletext.' ${ }^{14}$

According to the online Teletext Museum, it was in 1975 that the first teletext subtitles were displayed by Ceefax. However, teletext was not used much by the public until 1977 and later, when interest in the system picked up. Users had to either rent or purchase a new television set or buy a separate teletext decoder that could be used to access teletext information, such as the one shown in Figure 2.

The option of leasing or renting rather than purchasing television sets allowed an increasing number of households to access teletext, whose distribution rose at a considerable rate between 1978 and $1982 .{ }^{15}$ The service itself was free of charge and the practice of television rentals allowed consumers to access the service for little more than the cost of a standard colour television without teletext capabilities. Similarly, a number of other incentives helped increase the uptake of teletext, including "greater capital allowances" being granted for television sets and "more flexible rental contracts" of a minimum of three months compared with the six-month contracts required for other television sets. ${ }^{16}$ According to Rutter, there were 2.6 million Teletext users by $1984 .{ }^{17}$

10 'Windows on the World', The Home Computer Course, 1983, p. 264.

11 'Eng Inf: The Quarterly for BBC Engineering Staff,' No. 15, Winter 1983-1984.

12 Veith, p. 14.

13 Veith, p. 14.

14 McKinnon, p. 42.

15 Veith, p. 14.

16 Aumente, p. 31.

17 Dorian James Rutter, From Diversity to Convergence: British Computer Networks and the Internet, 1970-1995, PhD Thesis, The University of Warwick, 2005. 


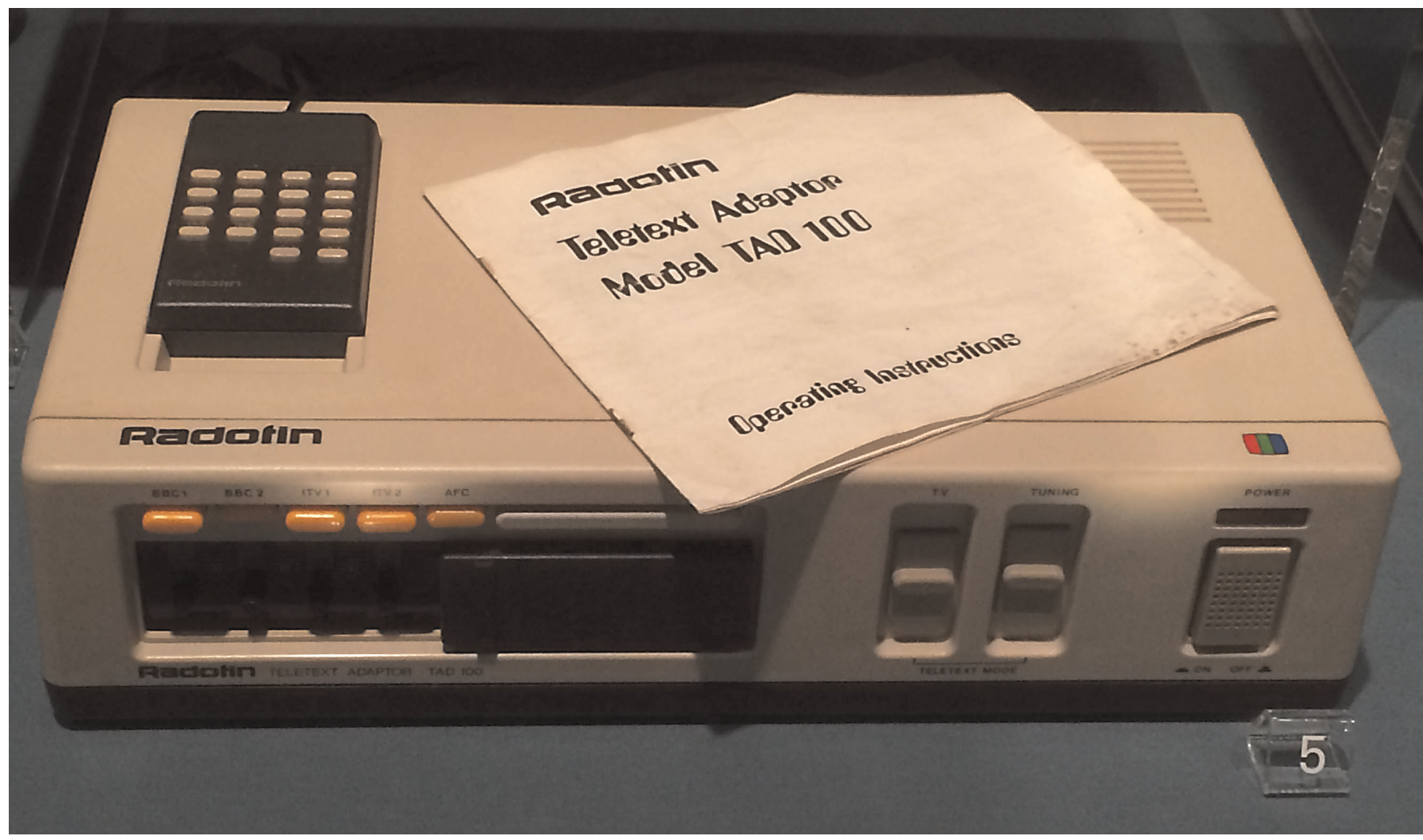

Fig. 2 Radofin Teletext Adapter Model TAD100 on display at the National Media Museum in Bradford, UK.

\section{Remediating 'OId'Media: Teletext's Pages and Magazines}

Although the television rental model facilitated the growth of teletext, manufacturers and the specialized press advocated the service's dissemination by referring to established (print) media. This remediation of vocabulary had the explanatory function of allowing the public to understand how to use the service.

For Adrian Robson, who was part of the first editorial team that worked on Ceefax, creating the databases of information included inventing a terminology that could "describe concepts that hadn't existed before." The main metaphor that was retained in relation with teletext was the 'page.' Robson notes that, "in the area of the service itself, initially, it was not at all certain that we would talk about pages; I think there was a certain amount of experimentation with other words, like screens...there was no word in common use for a fixed display. We eventually stuck to pages." 18

Manovich points to the importance of the 'page' metaphor in relation to the World Wide Web, stating that "the 1990s foregrounded the page as a basic unit of organization." ${ }^{19}$ Although the term is thus today closely associated with the Internet, 'page' was a commonly used term for teletext users as well as for the editorial team, who referred to it as part of the system's overall organization. In 1994, Paul Greff discusses in his article 'Teletext: New Life for an Under-Rated Source?' that teletext is an "electronic book, where pages can be called up on the television screen." 20

18 Mike Brown, 'Early Ceefax Subtitling: Adrian Robson Remembers...'

19 Lev Manovich, The Language of New Media, MIT Press, 2001, p. 16.

20 Paul Gregg, 'Teletext: New Life for an under-Rated Source?' in Bussiness Information Review, Vol. 11, No. 1, July $1994,63-74$. 
Using the term 'page' for teletext helped people understand the structure of the system by comparing it with older media, in particular books and magazines. ${ }^{21}$ Similarly, the notion of the 'magazine' was recycled to describe a 'group' of 100 teletext pages, with a total of eight magazines being available for each broadcast channel. ${ }^{22}$ By referring to the magazine, the makers of teletext encouraged audiences to understand the new technology through an analogy with previous media forms-implying that teletext's information pages functioned like print-based equivalents. This choice of terms in relation to the teletext page was outlined in an advertisement leaflet for a D.E.R receiver. Explaining the basic components of a teletext page, the advert underscored the system's rapidity to access new content enabled through the magazine structure.

In contrast to the static printed page, all teletext pages were broadcast in a constant cycle. If a user dialled up page 10, he or she would have to wait for that page to come up in the cycle to be displayed on the television screen. Teletext pages would cycle every 22 to 25 seconds per 100 pages, depending on the amount of data available in each magazine. Pages were not necessarily cycled in numerical order, and therefore, the company could broadcast the most popular pages in bunches within the cycle to allow them to be accessed more quickly. Both Ceefax and ORACLE succeeded in allowing viewers to interact with the system to find out the latest sports and news headlines, extending the possibilities of the broadcasters' capabilities before on-demand viewing and 24-hour news channels became widespread. This "immediacy" was highlighted in the D.E.R. advert as a "major feature of Teletext" that allowed users to "get the information when you want it, not at pre-set programme times." Users could call up flight arrivals before heading to the airport to pick up relatives, and although it was not as instantly updatable as Internet-based content, the interaction with linked information streams enabled users to gain another pathway to information beyond scheduled television content.

\section{Microcomputing and Television}

Parallel to teletext's rising popularity amongst the general public, other technologies and services were appearing on the home user market. The late 1970s and early 1980s in Britain saw increased technological development encouraged by the Conservative government under Margaret Thatcher's rule. The newly formed Conservative government had members who were keen to understand this phenomenon and realised that "something should be done." 23 The late 1970s had seen television programmes such as BBC Horizon's episode "Now the Chips Are Down" and ITV's The Mighty Micro series being aired. These television shows depicted a world of microcomputers taking over human tasks in the workforce, resulting in initiatives aimed at demystifying and promoting new technologies for a general public. The Conservative government sought to stimulate the development of computing and information technology in order to be seen as forward thinking but also as a way of showcasing Thatcher's new economic policies that encouraged entrepreneurial thinking. ${ }^{24}$ The government supported information technology research and development by increasing the amount of funding available from 1979 to 1984 by $£ 250$ million. This influx in funding along with other parallel technological developments led to the growth in microcomputing platforms including Clive Sinclair's ZX Spectrum, the BBC Microcomputer, and the Dragon $32 .{ }^{25}$

The BBC Microcomputer was associated with the BBC's Computer Literacy Project, which was set up to explain what microcomputers were, how they could be used in people's lives and how they linked to existing home technologies such as washing machines and television sets. The contents of the Computer Literacy Project were delivered via television

21 Jay David Bolter and Richard Grusin, Remediation, MIT Press, 1999.

22 ACORN Computers Limited, 'Teletext System User Guide' in ACORN Computers Ltd, 1983, p. 42.

23 Neil Selwyn, 'Learning Love the Micro: The Discursive Construction of "educational" to Computing in the UK, 1979-89' in British Journal of Sociology of Education, Vol. 23, Issue 3, 2002, 427-43.

24 For more about the politics in the UK during the 1980s with regards microcomputing see Thomas Lean, The Making of the Micro': Producers, Mediators, Users and the Development of Popular Microcomputing in Britain (1980-1989), unpublished PhD dissertation, University of

Manchester, 2008.

25 Lean. 
shows such as The Computer Programme and Making the Most of the Micro, as well as through home correspondence courses. ${ }^{26}$ In addition, magazines such as The Home Computer Course, published between 1983 and 1984, also helped to outline particular terms related to television use, teletext and microcomputers. ${ }^{27}$

Terms included those such as 'database,' which were explained further in issue 6 of The Home Computer Course. Using the example of teletext, the article states how "the Ceefax service on BBC1 and BBC2 and Oracle on ITV channels gives you access to a wealth of miscellaneous information, which is stored on a computer 'data base'. This is continuously updated so that the latest developments in news, weather, sport and even stocks and shares are instantly available at any time. ${ }^{28}$ For Manovich, the 'database' is one of the key identifiers of new media forms. ${ }^{29}$ Once again, we are reminded how television services that were connected to technologies of the 1980s were also situated with the 'new media' content of the time.

Similar examples in The Home Computer Course continue to show how the television was seen as a convergent technology or a 'new media' form. This time, the television and the VCR are discussed within the magazine as a way of explaining microprocessors and microcomputers. Microprocessors are discussed as being part of televisions in order to "provide very stable control to the colour television circuitry." ${ }^{30}$ The example highlights how there was a need to educate the public about microprocessors by explaining how they were already being used in commonly known technologies such as the television. The article's reliance on showing the role of the television in relation to other home technologies such as the VCR once again highlights the importance of understanding the growing convergence of these technologies. This convergence of technologies and services was explored further through the development of telesoftware.

\section{Convergent TV: Adding Teles oftware}

The term 'telesoftware' was coined by W.J.G. Overington in May 1977 to mean 'software at a distance' and was used in reference to transmitting programs via teletext services. ${ }^{31}$ Experimentation with telesoftware as a means for creating smart television sets was subsequently conducted in the late 1970s to see what this means of transmission could offer. ${ }^{32}$ However, it wasn't until the 1980s, with the arrival of microcomputers, that the public started to see how telesoftware could be used. Both the BBC and the Independent Broadcast Authority (IBA) experimented with telesoftware via Ceefax and ORACLE teletext services.

Already playing a central role within domestic space, the television set was often used as a display for an attached microcomputer. Consequently, it could act as part of a group of connected technologies that allowed users to download content. Instead of buying software on a cassette tape or floppy disk, the television audience could use existing teletext services to download content via their television sets and microcomputers, such as the BBC Microcomputer or ZX Spectrum. Telesoftware was not unique to teletext because it was also integrated into Prestel systems at the time, but the ability to download programs via the aerial instead of a telephone line came at a relatively low cost because additional telephone connection charges were not required.

Telesoftware programs were free to download once users had access to a teletext adapter for their microcomputer. Much like the earlier teletext adapters for television sets, teletext adapters for microcomputers allowed users to access teletext services through their machines as well as the television set. Once it was purchased, the teletext adapter was

26 Tilly Blyth, "The Legacy of the BBC Micro: Effecting Change in the UK's Culture of Computing" in Nesta, May 2012.

27 The Home Computer Course, Orbis Publishing 1983-1984.

28 'Domestic Science' in The Home Computer Course, 1983, p. 107.

29 Manovich, The Language of New Media, p. 220.

30 'Domestic Science.'

31 W.J.G. Overington, 'Telesoftware,' Computing, 5, 1977.

$32 \mathrm{~J}$. Hedger and R. Eason, 'Telesoftware: Adding Intelligence to Teletext', Proceedings of the Institution of Electrical Engineers, Vol. 126, Issue 12, December 1979, 1412-16. 
connected to the television aerial in order to receive teletext content. By plugging the teletext adapter into the microcomputer attached to a televisions set, the user was able to request teletext pages as he or she would on a teletext-enabled television. In combination with the adapter, the service now offered software to be downloaded by accessing the relevant teletext pages. By connecting the adapter to a microcomputer, the software could be used immediately or saved on a cassette tape or floppy disk to use at a later date. However, the current television sets did not have to have teletext capabilities because the external adapter allowed for access to the service.

One such device to have a teletext adapter was the BBC Microcomputer. The corresponding teletext adapter was available just over a year after the machine's initial release in 1981. The public's interest in teletext adapters and telesoftware services can be tracked through the letters sent to BBC magazines during the time, especially to the Acorn User magazines. One reader in the letters pages of the magazine writes in to ask whether the teletext adapter for the BBC Micro would allow him to use teletext services even though his current television set did not accept teletext transmissions. ${ }^{33}$ The reader further wanted to know whether he could run telesoftware programs without having to type them in.

The ease of using of BBC Micro's teletext adapter was highlighted in an article in the September 1983 issue of The Micro User magazine that stated, "to pick up the software off the air you need a Model B, an ordinary TV set and a

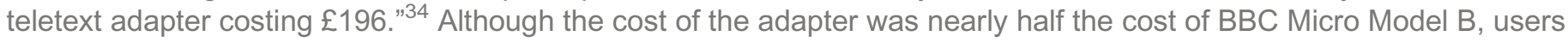
were interested in its potential and the links to the teletext system they had accessed prior to the release of the machine. Downloading software via telesoftware systems did not require any additional knowledge beyond how to execute basic microcomputer commands and how to understand the language of the pages, in addition to magazines that users had already grasped from standard teletext services.

This ease of use was also highlighted in relation to other teletext adapters for microcomputers such as the Volex TTX 2000S for the ZX Spectrum computer. An advertisement for the adapter in the January 1987 issue of Your Sinclair magazine states, "all you need is to plug in your VOLEX TTX 2000S adapter to receive 4-Tel from Channel 4, CEEFAX or ORACLE services," and "a simple procedure tunes the VOLEX adapter to your local teletext channels." 35 Finally, the connections to existing, known technology in the home were emphasized by stating, "absolutely no modification is necessary to TV or computer." The plug-in-and-use approach was also linked to the fact that telesoftware programs were broadcast as free for users of the adapter. Much like earlier discussions of teletext, the adapter was seen to facilitate extra capabilities of the television and microcomputer without specialist knowledge. In other words: the teletext adapter was pitched as contributing to a convergence of information technologies and advertised with the slogan that "information (is) at your fingertips."

However, despite some of the hype surrounding the potential use of the system, and the marketing rhetoric of simplified, convergent systems, telesoftware did have a short life. The BBC's own telesoftware service ran until 1989, when it became a victim of BBC savings. In the announcement outlining the closure of the telesoftware service in 1989, the BBC were keen to state, "Telesoftware was devised to provide software support to the BBC Micro in the early days, particularly in relation to Education programmes. It has always been a minor adjunct to, and not an integral part of, the BBC's commitment to the BBC Microcomputer." 36 The report continued to note that in May of 1989 sales of teletext adapters showed there to be just over 31,500 in domestic use, representing roughly $7 \%$ of the BBC Micro users as a target audience. These figures were disputed in an article in the October 1989 issue of The Micro User magazine with the "head of Ceefax, Blair Thomson [saying] this was one of the least popular Ceefax features, but telesoftware manager Jeremy Brayshaw disagreed." 37 The closure of the telesofware service also led to some disgruntled users writing in to the letters pages published in the same issue of The Micro User, where comments were made such as "I am sure I am not alone in saying my only reason for buying a teletext adapter for my BBC Micro was so that I could

33 'Your Letters,' Acorn User, August 1982, p. 38.

34 'It's on the Air', The Micro User, September 1983.

35 'Volex TTX 2000S', Your Sinclair, January 1987.

36 'BBC Announces Closure of Telesoftware Service,' 1989.

37 'Ceefax Telesoftware Axe Storm,' The Micro User, October 1989, p. 12. 
receive the programs broadcast in the form of telesoftware. We have a teletext television set so my adapter becomes redundant." ${ }^{38}$ Despite the uptake of the system by some members of the public, telesoftware did not prove to be a viable service, yet its history shows how this innovation enabled ways of expanding the television set in ways that are more commonly found integrated into these systems today.

\section{Conclusions}

Although it was used for a relatively short amount of time, the concept of telesoftware in the 1980s demonstrated the possibility of interactive connectivity via the home television set. However, the emergence and success of the Internet enabled people to access similar content in new ways. For the BBC, the viability of services such as telesoftware became no longer cost effective. The cost of adapters alongside the cost of the microcomputer meant that the system was generally not seen as an attractive additional option by home users.

In contrast to telesoftware services, teletext as a system did experience some growth in the early 1990 s. $^{39}$ Some teenagers used ITV and Channel 4's Teletext services as sources of information for news, pop culture, etc. Despite these uses of teletext, other contemporaries had already experienced it as having "blocky graphics" and looking "severely dated." Teletext services were phased out by many British television stations, including the BBC, in 2012.

Whereas mainstream histories can often focus on media developments of the masses, this media archaeological approach to teletext and telesoftware exposes other neglected histories of television such as home information technology. As a one-way source of information, teletext and telesoftware can, in many ways, be seen as precursor technologies to our current generation of smart televisions that allow for networked connections to other television services, apps and games. Yet it is these cycles of media change that allow us to trace the many histories of televisions and to expose the otherwise lost trajectories of technological developments that were sparked by national innovations, political and technological climates, product marketing and consumer habits. As this final video of Ceefax in its last broadcast days shows, teletext was an interesting experiment in how the public understood and experienced the use of databases, pages, and magazines in a televisual logic of distributed content.

\section{Biograph y}

Alison Gazzard is a lecturer in Media Arts and Education at the London Knowledge Lab, UCL Institute of Education, UK, and has published on location-based media, video game spaces and time, and British computer game histories. Her current research interests include platforms, media archaeology, game preservation and the use of archives in game creation.

38 'Telesoftware: The End of an Era?,' The Micro User, October 1989, p. 69.

39 David Gauntlett and Annette Hill, TV Living, Routledge, 1999, p. 165. 